\title{
Low-temperature fluid flow through sulfidic sediments from TAG: modification of fluid chemistry and alteration of mineral deposits
}

\author{
Rachel A. Mills and Trevor Clayton \\ Southampton Oceanography Centre, Southampton, UK \\ Jeffrey C. Alt \\ Department of Geological Sciences, University of Michigan, Ann Arbor
}

\begin{abstract}
Low-temperature fluid flow has been identified as an important component of the heat, mass and chemical flux at sites of active venting. One way to study the movement of water through hydrothermal deposits is to analyse the pore-fluids extracted from sulfidic sediments. The composition of diffuse flow fluids in one sediment core from the south of the active TAG mound reflects the dilution of high-temperature, black smoker fluids, with modification inside the mound during ongoing circulation. Fluid modification includes conductive cooling, removal of Si from solution and entrainment and removal of $U$ from seawater which can represent significant sinks of these elements. Precipitation of clay minerals and Fe-oxides is currently occurring within this sediment core generating ochreous type material subsurface. Extensive lowtemperature alteration of basaltic material at the core-top is apparent in conjunction with supergene enrichment of $\mathrm{Cu}$ and $\mathrm{Mn}$.
\end{abstract}

\section{Introduction}

Hydrothermal sediments are formed by various combinations of direct precipitation, plume fall-out and slumping of sulfidic, mound-derived material which is then admixed with background pelagic and biogenic sedimentation [e.g. Mills and Elderfield, 1995a]. The TAG hydrothermal field hosts the most extensive metalliferous sediment deposits along the Mid-Atlantic Ridge [Metz e al., 1988]. Sediment cover is up to several metres thick in places and consists of a complex mixture of sediment of differing origin. Sediments formed by plume fall-out and sulfide input have been described in detail [see Mills and Elderfield, 1995a].

One of the major questions still to be resolved in the study of mid-ocean ridge hydrothermal systems concerns the relative importance and composition of the low-temperature diffuse emissions of water in comparison with the spectacular high-temperature venting. Recently it has become apparent that diffuse flow at sites of active venting can represent the major flux of heat, water and chemicals at these sites [Rona and Trivett, 1992; Schultz et al., 1992]. The result of this low-temperature discharge is modification of the chemical fluxes issuing from active sites and alteration of the sulfide and sediment.

One way to tnvestigate low-temperature, diffuse flow is to collect pore-fluids from sediment cores. This approach has proved successful using short push cores deployed from submersible and results from a recent study at TAG are described here. Since some of the pore-fluid signal may be the result of diagenetic modification of the fluid, the solid phase must be studied in conjunction with the fluid.

Copyright 1996 by the American Geophysical Union.

Paper number 96GL02885.

0094-8534/96/96GL-02885\$05.00
The heterogenous substrate and kinetic limitation of fluid-solıd reactions will result in a complex mixture of sedimentary components and the conjugate pore-fluids.

The core described here is from the active TAG mound, $110 \mathrm{~m}$ to the south of the active black smoker complex. The coring site is in an area of diffuse flow delineated by a sparse anemone population and surficial hydrothermal crusts just north of a steep southwards dipping sedimented escarpment. Temperalures as high as $46^{\circ} \mathrm{C}$ were measured within the sediment column indicating advection of warm water through the sediment [heal flow site 2598-5, Becker et al., 1996]. Once on board, pore-fluids were extracted using a method adapted from Jahnke [1988]. All pore-fluid and solid phase analyses were carried out after returning to shore.

\section{Pore-fluids}

The $\mathrm{Mg}$ content of a hydrothermally derived fluid can be used as an index of seawater content by assuming that $\mathrm{Mg}$ is quantitatively removed from seawater during hydrothermal circulation through oceanic crust [Edmond et al., 1979] and that $\mathrm{Mg}$ behaves conservatively within the mound. Inter-element plots of $\mathrm{Mn}-\mathrm{Mg}$, ${ }^{87} \mathrm{Sr} /{ }^{86} \mathrm{Sr}-\mathrm{Mg}, \mathrm{Si}-\mathrm{Mg}$, and $\mathrm{U}-\mathrm{Mg}$ for sediment pore-fluids are shown in Figs. 1 a-d. $\mathrm{Mn}$ and $\mathrm{Sr}$ isotopic composition co-vary with $\mathbf{M g}$ demonstrating conservative mixing of the black smoker, hightemperature end-member with seawater during mixing within the mound. Mass balance calculations using $\mathrm{Mg}, \mathrm{Mn}$ and $\mathrm{Sr}$ isotopes suggest that the end-member black smoker fluid at TAG contributes
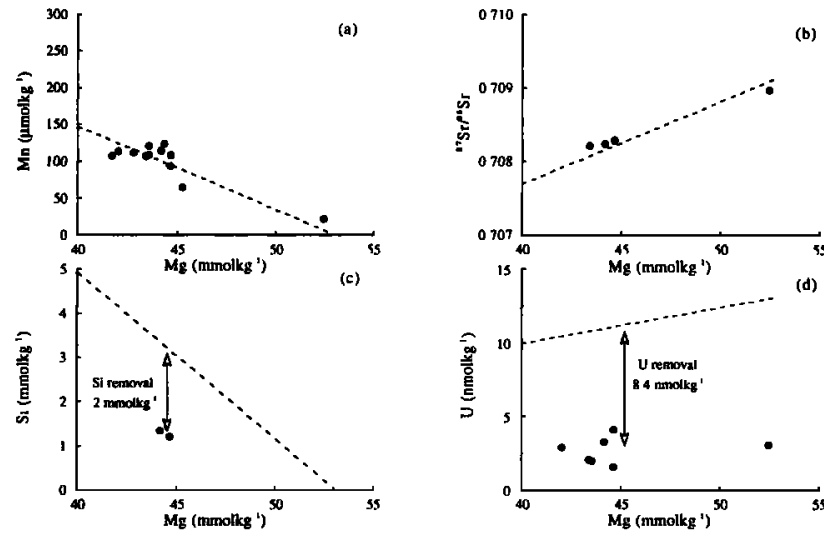

Figure 1. Plots of (a) $\mathrm{Mn}$, (b) ${ }^{87} \mathrm{Sr} /{ }^{86} \mathrm{Sr}$, (c) $\mathrm{Si}$ and (d) $\mathrm{U}$ against $\mathrm{Mg}$ concentration within pore-fluids from core 2598 . Dashed lines represent theoretical dilution of the black smoker end-member with seawater. End-member data are from Elderfield et al. [1993] and references therein. 
$15-18 \%$ to the diffuse flow collected at the southern periphery of the mound. While the covariation for $\mathrm{Mn}$ is generally linear, there is evidence for some uptake and release of $\mathrm{Mn}$ within the sediment reflecting the heterogeneity of the sediment porosity and local redox conditions. The pore-fluid heterogeneities must reflect the temporal and spatial variablity in the fluid flow regime through the sediment column that ultimately controls the redox conditions.

Concentrations of $U$ are much lower than that predicted by dilution of high-temperature fluids alone, demonstrating nonconservative behaviour and a substantial sink of $U$ within the mound during low-temperature circulation of mixed hydrothermal fluids and seawater. $U$ is quantitatively removed from seawater during deep hydrothermal circulation [Michard and Albarede, 1985] so the $U$ fixed within the mound is entirely of seawater origin. On average, $8.4 \mathrm{nmolUkg}^{-1}\left(2 \mu \mathrm{gkg}^{-1}\right)$ is removed from solution throughout the core. Large $U$ enrichments have previously been observed in altered sulfide bearing sediments from the TAG area and this has been interpretated as microbial uptake of $U$ from fluids in association with sulfide alteration [Mills et al. 1994].

The pore-fluid temperature range predicted by the chemical mass balance calculations, using specific heat data from Bischoff and Rosenbauer [1985] is $-100^{\circ} \mathrm{C}$ [A. Schultz, pers. comm., 1996] whereas the temperature measured down-core was $36-46^{\circ} \mathrm{C}$ [Becker et al., 1996] suggesting that extensive conductive cooling has occurred during fluid circulation within the mound. Si supersaturation will only occur via conductive cooling of the high-temperature fluid-seawater mixture [Tivey et al., 1995]. Measurements of Si concentration of pore-fluids suggest that removal of $\sim 2$ mmolkgis occurring within the mound (Fig. Ic) via precipitation of lowtemperature clay mineral assemblages and amorphous silica and quartz.

Large areas of the TAG mound exhibit diffuse flow. Estimates of the areal extent of such flow require a heat flux several times larger than that estimated for the black smoker complex [Schuliz and Elderfield, 1994]. Fluids analyzed here that are escaping from the southernmost periphery of the mound, some $110 \mathrm{~m}$ from the central black smoker complex, appear to be derived from high-temperature fluids that have undergone modification through entrainment and mixing of seawater into the permeable mound structure. Modification of the black smoker input to the ocean occurs via reactions within the mound (e.g. Si removal) and a sink for some seawater components (e.g. U) entrained into the mound.

\section{Core Description and Mineralogy}

The core studied is $21 \mathrm{~cm}$ in length with a green atacamite crust at the surface. Atacamite is a common supergene alteration mineral at the TAG site and many of the peripheral sulfide deposits are coated in atacamite and secondary sulphate minerals such as jarosite
[Hannington, 1993]. The core-top sediment also contains smectite, kaolinite, illite and quartz. The upper part of the core is coarse grained and contains visible sulphides and is separated from the lower coarse material by a fine grained $\mathrm{Fe}$-oxyhydroxide rich layer at $-16 \mathrm{~cm}$ depth. The lower half of the core consists of mainly coarse grained brown/green material with visible sulphides and a coarse red/brown layer at the core base. The two red layers consis of fine grained Fe oxy-hydroxides along with partially recrystallized Fe-oxides displaying dendritic and rounded structures, which may point to a colloidal or microbial origin (Fig. 2a). The oxides at $-16 \mathrm{~cm}$ depth exhibit compositional zonation, with growth bands parallel to the overall fabric of the sediment grains (Fig. 2b). These features are reminiscent of Liesegang rings supporting the inferred colloidal origin of much of the Fe-oxide material and the banded structures are precursors to agate-type textures commonly observed in TAG ochres and ODP silica/chalcedony mixtures [Humphris et al., 1996]. The core base has approximately equal amounts of nontronite and hematite present; the hematite suggests a fully oxidising environment.

Smectite is present throughout the core, the maximum at $-7 \mathrm{~cm}$ depth with minima in the red, Fe-oxide rich layers. The clay component is generally Al-poor, Fe-rich nontronite which is similar in composition to Galapagos and Mariana trough chimney nontronite [Kohler et al., 1994]. Both the Galapagos and Mariana chimney clays and the TAG clays exhibit low interlayer $K$ content which is significantly different from Galapagos mounds clays [McMurtry et al., 1983].

There is no calcite present within the core and all of the separated clays have low Ca contents. A mixture of $15 \%$ hydrothermal fluid and $85 \%$ seawater would have a pH of -6 [Tivey et al., 1995]; however the ongoing oxidation of sulfide material would generate much lower $\mathrm{pH}$ values in situ. The acidic upwelling fluids would dissolve any calcareous material present. Hydrothermal sedimentation rates in these areas are very rapid [Metz et al., 1988] resulting in minimal input of any material other than that slumped from the active mound deposit to the north of the coring site. Oxygen isotopic analyses of clay separates provide some insight to the origin of these materials. The surface sample, containing a mixture of nontronite, and minor kaolinite and illite, has a $\delta^{18} \mathrm{O}$ value of $+16.0 \%$ whereas a pure nontronite sample from $4-6 \mathrm{~cm}$ has a value of $+15.7 \%$. The high $\delta^{18} \mathrm{O}$ values preclude a detrital continental origin, and suggest low-temperature hydrothermal formation at the seafloor. The nontronite formed at about $80^{\circ} \mathrm{C}$ [Savin and Lee, 1988], probably from mixtures of hydrothermal fluids and seawater. This temperature is somewhat greater than the measured temperature of $\sim 46^{\circ} \mathrm{C}$, and may indicate temporal variations in fluid flux and temperature for diffuse flow. Sericite is a major component of basalt alteration within and beneath the TAG mound, and is a trace component of sulfide deposits within the mound [J.Alt,
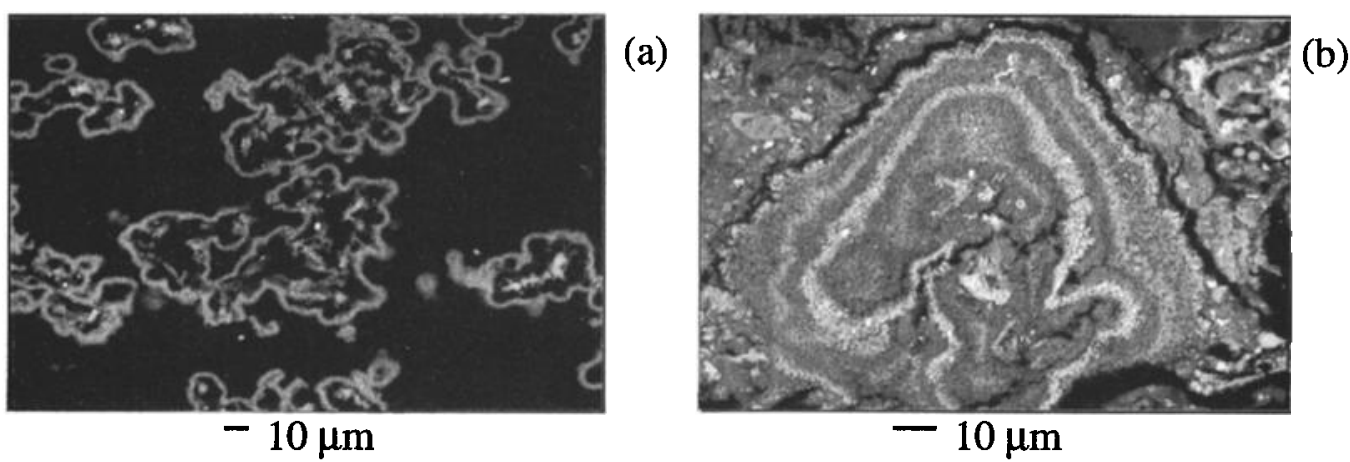

Figure 2. Back-scattered scanning electron microscope images of (a) dendritic Fe-oxide structures from the base of the core and (b) compositionally zoned Fe-silicate and Fe-oxide within hematite-bearing sediment at base of core. Bright layers are rich in Fe-oxy-hydroxides, duller layers are rich in Fe-oxy-silicates. 
unpublished data, 1995], so illite (and kaolinite) in the sediment core is most likely derived from breakdown of detrital mound material in the locally acidic conditions.

\section{Solid Phase Geochemistry}

The sediment is rich in $\mathrm{SiO}_{2}(34-46 \%)$ and $\mathrm{Fe}(6.7-43 \%$; Fig. 3a) throughout most of the core reflecting the high levels of sulfide, Fe-oxide, nontronite and other hydrothermal alteration products present. In situ precipitation of nontronite removes Si from solution resulting in a low-temperature sink for hydrothermal silica. Large areas of the TAG mound exhibit diffuse flow and therefore the Si sink via such reactions could be substantial. Magnesium con-

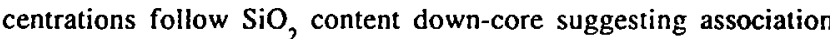
with low-temperature clay phases (Fig. 3a). Conversely, $\mathrm{Al}$ and $\mathrm{Ti}$ contents both are high at the core-top and decrease sharply downcore (Fig. 3b). The highest contents are just below the atacamite crust with abundances of up to $1.3 \% \mathrm{Al}$ and $1015 \mathrm{ppm} \mathrm{Ti}$, corresponding to the presence of kaolinite and illite within the core The co-variance of $\mathrm{Al}$ and $\mathrm{Ti}$ is high $\left(\mathrm{r}^{2}=0.998\right)$ if the basal sample is excluded. $\mathrm{Ti}$ and $\mathrm{Al}$ are relatively immobile elements and reflect the presence of highly hydrothermally altered basalt-derived material.

The supergene $\mathrm{Cu}$ enrichment at the surface is expected during oxidation of sulfide material; however, $\mathrm{Mn}$ appears to behave in a similar fashion to $\mathrm{Cu}$ with enrichment in the atacamite crust (1.45\%) and very low Mn content at depth. SEM studies show that there are discrete $\mathrm{Mn}$ rich phases associated with the atacamite. The Mn enrichment appears to be intimately associated with the supergene enrichment of the surficial sediment via precipitation of metals at the oxic interface. The deviations from conservative behaviour in Fig. la can be attributed to solid-pore-fluid interactions down-core.

$\mathrm{U}$ concentrations are high throughout the core (average $=12.4$ ppm) with the highest concentrations observed at the base of the core associated with nontronite and hematite $(34.4 \mathrm{ppm})$. Such high abundances are consistent with the removal of $U$ from seawater during circulation within the mound as suggested by the pore-fluid chemistry (Fig. 1d). The largest $U$ enrichment occurs in a portion of sediment core containing hematite and no detectable sulfide phases suggesting oxic conditions in this zone, ruling out $U$ reduction as a mechanism for enrichment.

The rare earth element (REE) content of material within the core varies by two orders of magnitude (0.16-19 ppm Nd). Chondritenormalized patterns for three representative portions of the core are shown in Fig. 4. REE patterns of various phases from the TAG mound have been well characterized and this allows identification of the different inputs 10 and alteration of core 2598 [Mills and Elderfield, 1995b].
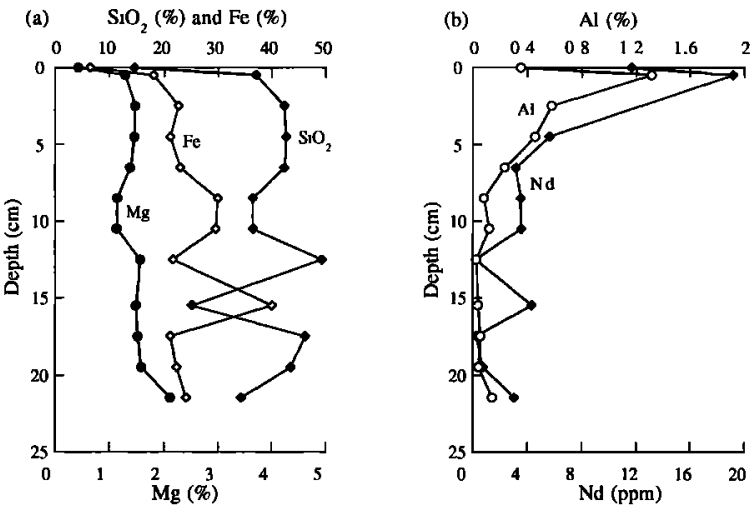

Figure 3. Down-core elemental distribution of (a) $\mathrm{Fe}, \mathrm{SiO}_{2}$ and $\mathrm{Mg}$ and (b) $\mathrm{Al}$ and $\mathrm{Nd}$.

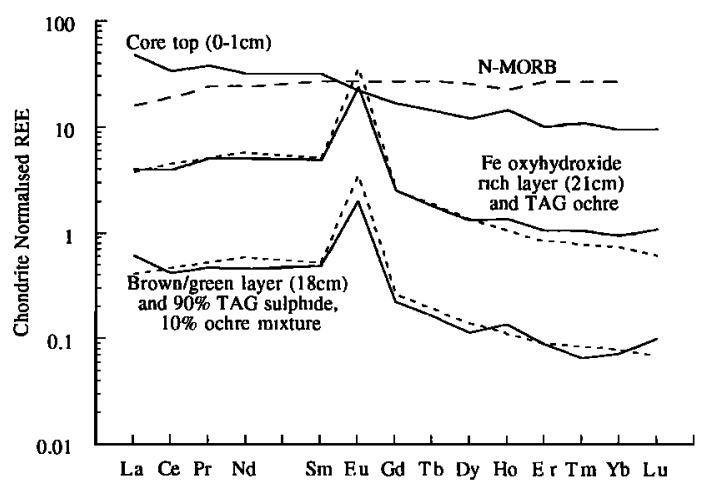

Figure 4. Chondrite-normalized REE patterns for three representative portions of core 2598. TAG ochreous material and a mixture of $90 \%$ sulfide and $10 \%$ ochre is shown for comparison, data from Mills and Elderfield [1995b]. N-MORB data are from Sun and McDonough [1989].

The Fe oxy-hydroxide rsch layers exhibit REE patterns that are identical to those of ochreous material from the TAG mound [Fig. 4; Mills and Elderfield. 1995b]. Ochreous material has been inferred to precipitate directly from low-temperature, evolved hydrothermal fluids at TAG [Mills and Elderfield. 1995b; Tivey et al., 1995] and this appears to be occurring at depths of $-16 \mathrm{~cm}$ and $-21 \mathrm{~cm}$ within core 2598. SEM imaging of sediment morphology suggests that the Fe-rich phases are of colloidal origin that form colloform and dendritic structures within the sediment, supporting the hypothesis of low-temperature Fe precipitation.

Brown/green material from the lower portion of the core exhibits extremely low REE contents with chondrite-normalized patterns that have large Eu anomalies and little evidence of any seawater influence. The REE patterns and contents $(0.16-0.77 \mathrm{ppm} \mathrm{Nd})$ in the lower core are intermediate between pristine sulfide and ochreous contents [Mills and Elderfield, 1995b] and the REE patterns are consistent with a mixture of $-90 \%$ sulfidic material and $10 \%$ ochreous material within the lower core (Fig. 4).

The upper core exhibits high REE concentrations (up to $19 \mathrm{ppm}$ Nd) and flat chondrite-normalized patterns. Such patterns have not been observed previously at TAG and are similar to observations from Snake Pit [Gillis et al., 1990] and Green Seamount [Alt, 1988]. Throughout the core there is a close correlation between REEs (Nd) and Al $\left(r^{2}=0.844\right.$; Fig. $\left.3 b\right)$ suggesting that the majority of the REEs are held within the aluminous clay mineral phases derived from basaltic material. The MORB-type REE pattern for the surface sample is also consistent with such an origin, though the REE patterns are light-REE enriched and heavy-REE depleted compared with MORB values of Sun and McDonough [1989]. This LREE enrichment suggests that the alteration of basalt debris by hydrothermal fluids at $-80^{\circ} \mathrm{C}$ results in a fractionated REE pattern. The presence of basaltic debris and alteration products at the top of the southern escarpment supports the hypotheses, put forward by Humphris et al. [1995], of a complex episodic volcanic and tectonic history at the TAG mound.

\section{Conclusions}

Studies of diffuse flow have been limited to date because collection of low-temperature fluids without entrainment of large amounts of ambient seawater is technically difficult. We have demonstrated that collection of pore-fluids from sedimented areas of diffuse flow provides a powerful method of fluid collection. In addition, the solid phase through which the fluids are percolating can be studied allowing assessment of the complex interactions between hydrothermal fluids and the mound substrate during low-temperature 
circulation. Pore-fluids collected from an area of diffuse flow approximately $110 \mathrm{~m}$ south of the active vent complex at TAG demonstrate that these fluids are mixtures of high-temperature black smoker fluid and ambient seawater. During mixing within the TAG mound, the fluid composition is modified resulting in the removal of $\mathrm{Si}$ and $\mathrm{U}$ from solution and enrichment in the solid phase.

Mineralogical and geochemical considerations of the solid phase have generated a model for sediment evolution which involves several distinct processes: (1) slumping of sulfidic, and basaltic material over the mound surface; (2) circulation of lowtemperature fluids through the mound; (3) alteration of sulfide and basalt material; (4) precipitation of Fe oxides and nontronite; (4) supergene formation of atacamite and $\mathrm{Mn}$ oxides at the seawatersediment interface; (5) changes in the porosity of the sediment and generation of heterogeneous redox conditions.

Acknowledgements. P.A Rona is thanked for providing dive time at TAG. RAM would like to thank the captain, officers and crew of the RV Allantis II and DSRV Alvin during leg 129-5 for all their assistance with sample collection. Thanks are extended to $P$ Smith and $M$ Walker for construction of sediment sampling equipment, $P$ Rona, $K$ Becker and R Von Herzen for collecting samples and providing heat flow data, $R$ Evans, J-L Chariou and J-P Donval for assistance with pore-fluid extractions. $R$ Jones and $J$ Ford for preparation of polished sections, B Cressey, I Croudace, H Cussen, J Harley, N Higgs, S Holley, T Kemp, A. Lucas, R Saunders, A Tappin and A Williams for help with analyses, $H$ Elderfield, $C$ German, $R$ Nesbitt and $M$ Palmer for providing laboratory facilities. JCA acknowledges J R O'Neil for the use of his laboratory. This manuscript benefited from comments from $\mathrm{H}$ Chiba, $\mathrm{W}$ Goodfellow and an anonymous reviewer.

\section{References}

Alt, J.C., The chemistry and sulfur isotopic composition of massive sulfide and associated deposits on Green Seamount, Eastern Pacific. Econ. Geot., 83. 1026-1033, 1988

Becker K, R. Von Herzen, J. Kirklin, R. Evans, D. Kadko, M. Kinoshita, O. Matsubayashi, R. Mills, A. Schultz and P. Rona, Conductive heat how at the TAG active hydrothermal mound: Results from 1993-1995 submersible surveys, Geophys. Res. Lett., this volume.

Bischoff, J.L., and R.J. Rosenbauer, An empirical equation of state for hydrothermal seawater (3.2 percent $\mathrm{NaCl}$ ), Amer. J. SCl. 285, 725-763, 1985.

Edmond, J.M., C. Measures, R.E. McDuff, L.H. Chan, R. Collier, B. Grant, L.I. Gordon, and J.B. Corliss, Ridge crest hydrothermal activity and the balances of the major and minor elements in the ocean: the Galapagos data, Earth Planet. Sci. Lett., 46, 1-18, 1979.

Elderfield, H., R.A. Mills, and M.D. Rudnicki, Geochemical and thermal fluxes, high-temperature venting and diffuse flow from mid-ocean ridge systems: the TAG hydrothermal field, Mid-Atlantic Ridge $26^{\circ} \mathrm{N}$, Geol. Soc. Spec. Publ., 76, 295-307, 1993.

Gillis, K.M., A.D. Smith, and J.N. Ludden, Trace element and Sr-isotopic contents of hydrothermal clays and sulfides from the Snake Pit hydrothermal field: ODP site 649. Proc. Ocean Drill. Prog.. Sci. Res., 106/I09. 315-319, 1990.
Hannington, M.D., The formation of atacamite during weathering of sulfides on the modem seafloor, Can. Mineral., 31, 945-956, 1993.

Humphris, S.E., P.M. Herzig. D.J. Miller, et al. The internal structure of an active sea-floor massive sulphide deposit, Nafure, 377, 713-716, 1995.

Humphris, S.E., P.M. Herzig, D.J. Miller, et al., Proc. Ocean Drill. Prog., Inut Rep., 158, 194, 1996.

Jahnke, R.A., A simple, reliable, and inexpensive pore-water sampler, Limnol Oceanogr., 33, 483-487, 1988.

Kohler, B., A. Singer, and P. Stoffers, Biogenic nontronite from marine white smoker chimneys, Clays Clay Mineral., 42, 689-70I, 1994.

McMurtry, G.M., C.-H. Wang, and H.-W. Yeh, Chemical and isotopic investigations into the origin of clay minerals from the Galapagos hydiothermal mounds field, Geochim. Cosmochin. Acta. 47, 475-489. 1983.

Metz, S., J.H. Trefry, and T. Nelsen, History and geochemistry of a metalliferous sediment core from the Mid-Atlanuc Ridge, Gesschim. Cosmochim. Acka, 48, 47-62, 1988.

Michard, A.. and F. Albarede, Hydrothermal uranium uptake at ridge crests Nature, 317, 244-246, 1985

Mills, R.A., and H. Elderfield, Hydrothermal activity and metalliferous sediments, in Physical. Chemical. Biological and Geological Imteractions within Hydrothermal Systems, edited by S.E. Humphris, R. Zierenberg. L. Mullineaux, and R. Thonson, pp. 392-407, AGU Monograph. 1995a

Mills. R.A., and H. Elderfield, Rare earth element geochemistry of hydrothermal deposits from the active TAG mound, $26^{\circ} \mathrm{N}$ Mid-Atlantic Ridge, Geochim. Cosmochim. Acta, 59, 3511-3524, 1995b.

Mills, R.A., J. Thomson, H. Elderfield, R.W. Hinton, and E. Hyslop. Uranium enrichment in mctalliferous sediments from the Mid-Atlantic Ridge, Eurth Planet. Sci. Lelt, 124, 35-47, 1994

Rona, P.A., and D.A. Trivett, Discrete and diffuse heal transfer at ASHES vent field. Axial Volcano. Juan de Fuca Ridge, Eurth Plamet. Sir. Letl.. 109. 57-71, 1992.

Savin. S.M., and M. Lee. Isotopic studies of phyllostlicates. in Hrdrous Phyllosslicutes, pp. 119-123, Mineral. Soc. Amer, Washington. 1988

Schultz, A . J.R Delaney, and R E McDuff. On the partilioning of heat flux between diffuse and point source seafloor venting. $J$ Geophys Res.. 97. 12229-12314, 1992.

Schultz. A.. and $H$ Elderfield, Direct measurement of the physics and chemistry of diffuse and high-temperature effluent at TAG and Broken Spur vent fields, Eors, Trams Amer. Geophys U., 75, 308. 1994

Sun. S.S., and W.F. McDonough, Chemical and isotopic systematics of ocean basalıs. Implıcations for mantle composition and processes. Gerol. Soc Spec Publ., 42, 313-345. 1989.

Tivey, M.K., S.E. Humphris, G. Thompson, M.D. Hannington, and P.A Rona Deducing patterns of fluid flow and mixing within the active TAG mound using mineralogical and geochemical data, J. Geophys. Res., /00, 1252712555, 1995

R. A. M1lls and T. Clayton, Southampton Oceanography Centre, Southampton, SO14 3ZH, UK (e-mail: ram1 @soc.soton.ac.uk)

J. C. Alt, Deparment of Geological Sciences, University of Michtgan, Ann Arbor, MI 48109, USA

(Received October 2, 1995; revised April 23, 1996;

accepted June 7, 1996.) 